\title{
Research on Environmental Awareness of the Textile and Clothing Professional Education Penetration
}

\author{
Die $\mathrm{Hu}^{1}$ \\ ${ }^{1}$ Jiangxi Institute of Fashion Technology, Nanchang, Jiangxi, 330201
}

KEYWORDS: Textile and Clothing; Professional Education; Green; Research

\begin{abstract}
The rapid development of the national economy, society becomes prosperous, people's living standards gradually improved, the consumption level is also rising on textile clothing requirements are also increasing, with particular emphasis on product quality textile clothing. Social advancement of technology, textile and garment production increasingly skilled, mechanized way, fast, convenient, efficient, but also accompanied by the textile and garment issue, in modern textile and garment production process, produced a series of environmental pollution in the consumption process affect human health and so on, which is to tell a concept: the concept of green, which is also in the textile and clothing professional education needs to permeate the awareness of environmental protection.
\end{abstract}

\section{Today's Textile and Clothing Professional Education on Environmental Awareness of the Weak}

Textiles and clothing, a warm essential everyday clothing, such as socks, warm clothing, and so on textile clothing. Warm clothing, textile and garment one, we all know, has a warm effect, in terms of product quality requirements cannot be added to substances harmful to health, it will not only affect the use of textile and clothing, and more important is harmful to human health. But in the professional education in textile and clothing, but there are few universal environmental awareness, we can see people in the textile and garment green awareness is very weak.

Green refers not only produced by the textile and garment production can not pollute the environment, adverse impact on the social environment, not to endanger human life and health. So choose clothing and human health components and is causing environmental pollution has a direct relationship. Used in the textile and garment production process if the fabric does not meet the requirements of the national fabric, it might cause the body to produce allergic reactions, causing skin diseases and certification; dye used in the textile and garment processing or processing excess dye ingredients, the chemical composition of the textile and clothing left after processing more odor thick, long-wearing such clothing, harmful chemicals will slowly immersed in the skin, leading to the body to produce disease. in addition, the textile and garment processing procedure China excessive use of chemicals, chemical waste and waste produced after the completion of the final garment processing easy processing, easy to cause environmental pollution discharged. Therefore, in the textile and clothing professional education not only to teach professional knowledge textile and clothing, and more important to the popularity of apparel production and processing of chemical knowledge, properly handle the textile and garment production and processing, to achieve good quality produced by the textile and garment, It will not cause harm to humans and will not pollute the environment. In the textile and clothing professional education 
students to organize awareness apparel harmful substances: dyes, formaldehyde content, $\mathrm{pH}$ value, alkylphenol ethoxylates, phthalates vinegar, allergenic disperse dyes, the total amount of lead and cadmium, hexavalent chromium, nickel release, pentachlorophenol, organic tin compounds, which is banned azo dyes must do the project.

Green, in today's society and called for international issues. To achieve the social environment, the international environment green, we need everyone from little things. Textile and clothing professional education to cultivate awareness of environmental protection is everyone needs to be done. In recent years, fur, leather hot, chasing a lot of people, indeed, fur, leather is very beautiful, wear very warm, but the clothing material is used in people feel cold, animal fur. China is taking the road of sustainable development, textile and clothing from animal fur produced is contrary to the concept of sustainable development.

Social development, international trade organizations to strengthen, and now international advocacy is green culture concept, to China and the world, and international cultural integration, it is necessary to popularize the green philosophy of education, textile and clothing professional education is no exception.

The ultimate goal is to chase the interests of enterprises, many enterprises in order to enhance the value of the benefits inside, simply ignore many of the problems in the textile and garment, which is the development of textile and garment industry is extremely unfavorable. For now, the country with respect to the past has made great progress in the textile and garment green supply chain management, but compared with other countries, there is still a great distance, mainly in the textile and garment green trade management. This is also the textile and clothing professional education needs to be strengthened in part, to further improve and develop the textile and garment trade in green management knowledge.

\section{How to Infiltrate the Environmental Awareness of Professional Education in Textile and Clothing}

In fact, a long time ago in the textile and clothing in the professional education of environmental protection as a new fashion concepts into the textile and garment, the environmental awareness of fashion as a theme, but with the rapid pace of economic and ignored. This approach can now regain the environmental awareness into the teaching apparel, textile and clothing and perhaps a professional education in a major bright spot. Further Green is jointly initiated by the world, will be injected into the awareness of environmental protection in the textile and clothing professional education across the board, and that China adheres to the road of sustainable development philosophy is consistent.

Green consciousness is actually a return to nature approach, which is now the source of many of the best international designer's creative ideas and inspiration. Nature is the source of all inspiration, the designer can stimulate environmental awareness infinite imagination, pass out through the designer's dresses green concept works, which inspired people's awareness of environmental protection has a powerful force. If reflects the concept of environmental protection in the textile and garment design, garment production after it, consumers can not only green "wear" on the body, reflecting the concept of green, as well as textile and clothing to more people by passing the green concept promote social and the public to develop environmental awareness.

The "green" is worn textile and clothing professional education in a new concept of education, environmental awareness is to penetrate into the textile and clothing professional education in an effective way. The "green" wore reflect environmental awareness is reflected in another textile and apparel fabrics of choice, natural fiber fabric selection is from the beginning of the 1980s have been 
using up to now, is the concept of green natural delivery, which most designers also made from natural fiber fabric is one important reason; in addition to the expansion of textile and clothing in the fabric of choice, and to achieve the environmental protection requirements, so there are natural fibers of cotton, linen, cloth and other fabrics, to textile and clothing better development, and in line with the concept of green, so a positive textile designer will put environmental awareness to the textile and apparel fabric development and production. Such issues are also in the textile and clothing professional education needs extra attention.

The purpose of education is to cultivate more talents for the development and needs of the community to make a contribution, while promoting personal growth. Textile and clothing professional education not only to make personal master of all textile and clothing techniques, skills and knowledge, more important is the transfer of green concepts through professional education to all people. The main purpose of education is to disseminate culture, deliver value system. To develop awareness of environmental protection is not accomplished overnight thing, takes time to accumulate, it requires individual approval. The so-called habit, first recognized the concept of the green, and then through the guide textile and clothing day after day, professional education, patience, be able to establish environmental awareness

In order to better environmental awareness will penetrate into the textile and clothing professional education, in addition to professional education in the normal time will be a lot of green to introduce the concept of professional education in the textile and clothing, will also be environmental awareness as a professional textile and clothing focus on extending direction of education, this can be arranged at the middle school period or rest period, interspersed of learning, neither take up too much time resources, resulting in the phenomenon cart before the horse, as well as the popularity of environmental awareness.

\section{Conclusion}

Green is the fundamental foothold textile and clothing professional education, which is the textile and clothing must adhere to the road, but China must continue on the path of the road. But now the textile and clothing professional education awareness of environmental awareness is not enough, this is the Chinese education must address the problem. Green is the path of sustainable development, environmental awareness must penetrate into the green textile and clothing professional education.

\section{Reference}

[1] Wang Gang. Education Textile and Clothing Import Thinking Green Environmental Awareness [J]. Intellect, 2013, Eighty-Six Past Six P.M..

[2] Yao Guizhen. Textile and Clothing Import Education Thinking Green Environmental Awareness [J]. Shandong Textile Economy, 2010,09: 18-21.

[3] Chen Xiadai. Next Green Trade Barriers Shaoxing Textile and Garment Export Analysis [D]. Zhejiang University of Technology, 2014.

[4] Zhang Meijie. Ecological Clothing Design Research [D]. Jiangnan University, 2009.

[5] Yu Hongming. Green Century Textile Industry Green Marketing [D]. Suzhou University, 2004. 